\title{
Structural Alterations in Mechanically Activated Malachite
}

\author{
T. TUNÇ AND K. YILDIZ \\ Sakarya University, Metallurgical and Materials Engineering, Sakarya, Turkey
}

\begin{abstract}
Malachite, a copper carbonate hydroxide mineral with the formula $\mathrm{Cu}_{2} \mathrm{CO}_{3}(\mathrm{OH})_{2}$ was mechanically activated for different durations in a planetary mill and analyzed by means of scanning electron microscopy, X-ray diffraction, Fourier transform infrared spectroscopy and particle size analysis to investigate the structural alterations in malachite structure. The results showed that decrease in intensity of the X-ray diffraction peaks and some alterations in carbonate and hydroxyl units of malachite occurred with increase in mechanical activation duration.
\end{abstract}

DOI: $10.12693 /$ APhysPolA.125.177

PACS: 81.20.Wk, 61.43.Gt, 91.60.Ed

\section{Introduction}

Malachite and azurite are known as hydroxyl-carbonate form of copper and have $\left[\mathrm{Cu}_{2}(\mathrm{OH})_{2} \mathrm{CO}_{3}\right]$, $\left[\mathrm{Cu}_{3}\left(\mathrm{CO}_{3}\right)_{2}(\mathrm{OH})_{2}\right]$ formulation, respectively [1]. In these minerals copper occurs in oxide form and other oxide forms are tenorite $(\mathrm{CuO})$, chrystocolla $\left(\mathrm{CuSiO}_{3} \cdot 2 \mathrm{H}_{2} \mathrm{O}\right)$ [2], and chalcocite $\left(\mathrm{Cu}_{2} \mathrm{O}\right)$ [3]. Copper is in divalent state in these minerals [2]. Copper ore generally occurs in nature in the form of sulfide and oxide minerals $[3,4]$ and copper oxide and carbonate ores represent $10 \%$ of the total world copper reserves [5]. Chalcopyrite $\left(\mathrm{CuFeS}_{2}\right)$, bornite $\left(\mathrm{Cu}_{5} \mathrm{FeS}_{4}\right)$ [3], chalcocite $\left(\mathrm{Cu}_{2} \mathrm{~S}\right)$ [6], cubanite $\left(\mathrm{CuFe}_{2} \mathrm{~S}_{3}\right)$, and enargite $\left(\mathrm{Cu}_{3} \mathrm{AsS}_{4}\right)$ [7] get involved in the group of sulfide minerals. From these ores copper is produced via hydrometallurgical and pyrometallurgical methods [3]. Bingöl and Canbazoğlu stated that copper was the first metal that hydrometallurgical process was applied to [8]. The solutions used in leaching of malachite for extraction of copper are sulphuric acid [8], $\mathrm{NH}_{3}-$ -saturated water [3], ammonium hydroxide-ammonium carbonate combination [2]. Samouhos et al. studied reduction of $\mathrm{CuO}$ that is present in the malachite to metallic $\mathrm{Cu}$ by microwave and carbothermic reduction by using lignite and graphite as a reducing agent [5]. Besides these studies some researchers have focused on characterization of malachite. Frost et al. studied thermal decomposition of malachite and azurite by means of thermal, mass spectrometric, and infrared emission analyses and concluded that decomposition phenomenon occurred in six overlapping stages that differ in temperature [1]. Thermodynamic properties of copper carbonates were studied by Kiseleva et al. [9] and thermogravimetry of mechanically activated malachite and physical mixture of malachite and calcite were studied by Wieczorek-Ciurowa et al. [10] to illuminate the mechanism for further process. Nowadays malachite have been although still used for production of copper, in ancient time it was used as pigments in manuscripts, glasses and glaze [1]. It is possible to start some reaction that cannot be started at room temperature by mechanical activation [11]. Energy accumulation at surface or in the bulk can be obtained because of the further energy supply to the refined particle [12].
Mechanical activation process has been used by many researchers to accelerate the reaction [13].

\section{Experimental methods}

Mechanical activation of the ore was performed in a Planetary Mono Mill Pulverisette 6 using $250 \mathrm{~mL}$ tungsten carbide (WC) grinding bowl and WC balls that weighed $8.13 \mathrm{~g}$ and had $10 \mathrm{~mm}$ diameter. For determining of the effect of milling duration on sample structure in each experiment, $13 \mathrm{~g}$ sample was used and mass to ball ratio and the speed of main disk were kept constant at 1:25 and $600 \mathrm{rev} \mathrm{min}^{-1}$, respectively. Milling process was carried out in dry conditions for $0,30,45$, and $90 \mathrm{~min}$. X-ray diffraction (XRD) analysis was performed using a Rigaku Ultima X-ray diffractometer and $\mathrm{Cu} K_{\alpha}$ radiation. TESCAN VEGA scanning electron microscope was used for morphological analysis of non-activated and activated samples. Shimadzu FTIR spectroscopy was used for FTIR analysis and Mikrotrac S3500 was used for particle size distribution analysis of non-activated and activated (30, 45, and $90 \mathrm{~min})$ malachite samples.

\section{Results and discussion}

XRD analysis of non-activated and activated for 30, 45, and 90 min malachite samples are given in Fig. 1a and $\mathrm{b}$, respectively. Figure $1 \mathrm{~b}$ also shows comparative patterns of the samples with reference to non-activated one in $14^{\circ}-40^{\circ}$ interval. The non-activated and activated samples are composed of quartz and malachite that differ in intensity. It can be said from the XRD analysis that quartz is the dominant phase in the structure. With increase of the duration of mechanical activation, the structure began to change its structure and tended to be amorphous. After 30 min of activation, diffraction patterns of the malachite disappeared and peaks of the quartz started to be broadened, decreased in intensity and shifted in angle. These phenomena was caused by interactions between powders and grinding media that occur during mechanical activation which associated attrition and impact reveal imperfection of the structure and finally amorphization [12]. 


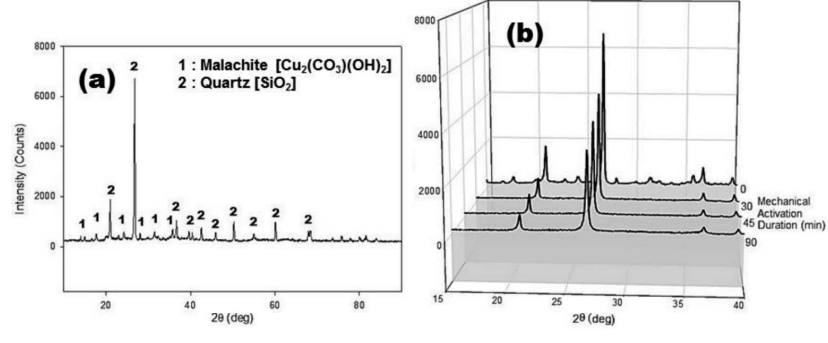

Fig. 1. X-ray diffraction analysis of (a) non-activated and (b) activated malachite samples.

Scanning electron microscopy (SEM) analyses of the samples are given in Fig. 2 and particle size distribution graphics were placed on the right side of the micrographs. Ninety, fifty, and ten percent values of the particle are given under the related graphs of the samples. Non-activated malachite has large and small, angled particles which in consequence of intensive milling tended to decrement in size and rounding in shape. As seen from the values, size decreased from $52.59 \mu \mathrm{m}$ to $4.69 \mu \mathrm{m}$ after 30 min. Prolonged milling time caused increased particle size. During high energy milling three stages were observed; new surface area formation is proportional to the energy input in the Rittinger stage, new surface area produced is not proportional to the energy input in aggregation stage and decrease of particle surface area because of the particle interaction in agglomeration step [14]. So it can be said that after 30 min of mechanical activation agglomeration phenomena occurred.
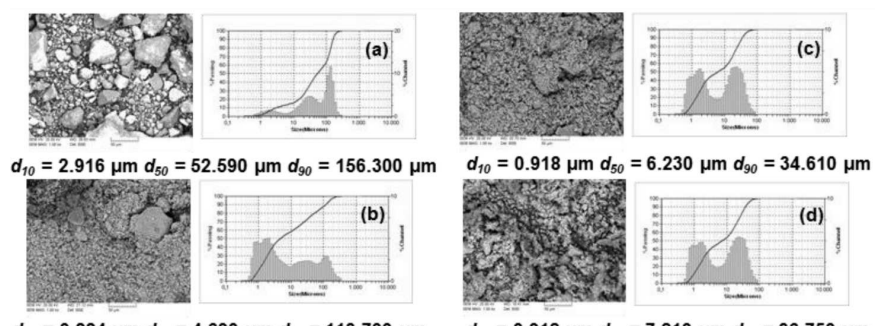

$d_{10}=0.884 \mu \mathrm{m} d_{50}=4.690 \mu \mathrm{m} \mathrm{d} d_{90}=113.700 \mu \mathrm{m}$

$d_{10}=0.912 \mu \mathrm{m} \mathrm{d} d_{50}=7.210 \mu \mathrm{m} d_{90}=36.750 \mu \mathrm{m}$

Fig. 2. SEM micrographs and particle size analysis diagram of (a) non-activated and activated for (b) $30 \mathrm{~min}$, (c) $45 \mathrm{~min}$ and (d) $90 \mathrm{~min}$ malachite samples.

The Fourier transform infrared spectroscopy (FT-IR) analyses of the samples are given in Fig. 3 . The spectra of FT-IR were recorded in the mid-infrared range between 4000 and $700 \mathrm{~cm}^{-1}$. $850-700 \mathrm{~cm}^{-1}$ interval is given as a separate graph. All samples have intensive bands between 1700 and $700 \mathrm{~cm}^{-1}$. At $1647.21 \mathrm{~cm}^{-1}, \quad 1504.48 \mathrm{~cm}^{-1}, 1392.60 \mathrm{~cm}^{-1}$, $1006.84 \mathrm{~cm}^{-1}, \quad 910.40 \mathrm{~cm}^{-1}, \quad 794.67 \mathrm{~cm}^{-1}$, and $779.24 \mathrm{~cm}^{-1}$ centered bands were determined for non-activated malachite sample. For mechanically activated samples, the intensity and position of the peaks somewhat different. Remarkable changes for the bands that between $1100-750 \mathrm{~cm}^{-1}$ is increment in band intensity with increasing milling time until 90 min. For 90 min activated sample the intensity of the bands is lower than the 45 min activated one.

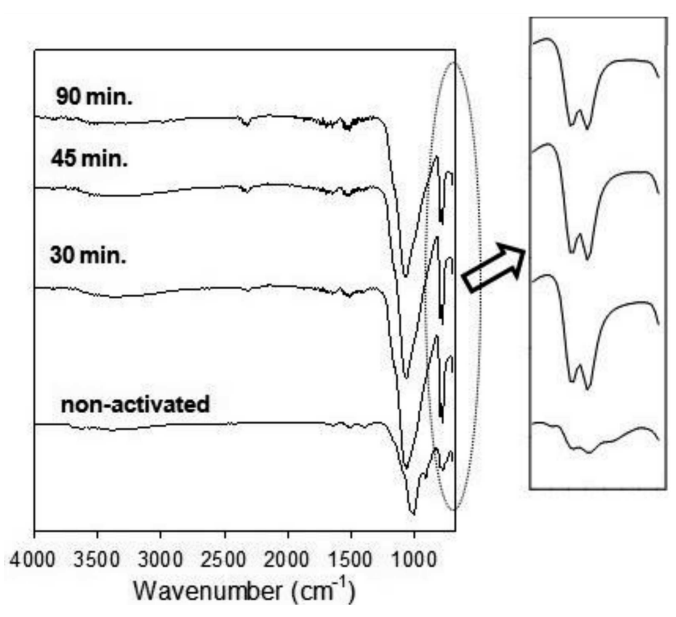

Fig. 3. FT-IR analysis of the malachite samples.

Frost et al. studied some minerals that belong to rosasite group by means of the Raman and infrared spectroscopy and indicated that spectral patterns for these minerals are similar to malachite. They found two $\mathrm{OH}$ stretching vibrations at $\approx 3401$ and $3311 \mathrm{~cm}^{-1}$ [15]. Molchan et al. synthesised malachite and characterized it with FT-IR as well as other techniques. Weak peaks at 3400 and $3316 \mathrm{~cm}^{-1}$ were found associatively to $\mathrm{OH}$ absorption [16]. Well-defined bands could not been determined for non-activated and activated malachite samples but broad bands exist in the range of $3305-3201 \mathrm{~cm}^{-1}$ that indicate $-\mathrm{OH}$ stretching vibration area that refer in the literature. With mechanical activation, broad bands tended to become linear. This region is stated as sensitive to dehydroxylation temperature [17]. Because of the attractions between grinding bowl-balls-powders local temperature may increase during mechanical activation [12]. So it can be said that by observing the linearity of this area, dehydroxilation proceeds during 30 and $45 \mathrm{~min}$ of activation but is not completed after 90 min of activation observing a weak broad band for this sample.

$1647.21 \mathrm{~cm}^{-1}$ centered shifted to $1651.07 \mathrm{~cm}^{-1}$ after 30 min of mechanical activation and preserved its position for other durations. This position is assigned as $\mathrm{H}-\mathrm{O}-\mathrm{H}$ bending modes [18], water deformation modes [15] or indicative for existence of crystal water molecule [18]. After mechanical activation of the sample despite the changes at the band position, the band still exists which demonstrated that the sample contains crystal water but has not the same bond strength.

$1504.48 \mathrm{~cm}^{-1}$ and $1392.60 \mathrm{~cm}^{-1}$ centered bands attributed to $v_{3}$ asymmetric $\left(\mathrm{CO}_{3}\right)^{2-}$ stretching modes of malachite. Frost et al. reported these bands at about 1500 and $1400 \mathrm{~cm}^{-1}$ [15]. For non-activated, 30 and 45 min activated sample these two bands have definable 
character, whereas 90 min activated sample was absent in point of centered at $1400 \mathrm{~cm}^{-1}$ band. $1504.48 \mathrm{~cm}^{-1}$ centered band shifted to $1508.33 \mathrm{~cm}^{-1}$ after $30 \mathrm{~min}$ of activation and remained in this position. If a band center shifts to higher position it means that the bond strength decreases [12]. From these results it can be said that partial decomposition and dehydroxylation were achieved. From the movement of band centers to higher position, the X-ray analysis confirmed nearly total amorphization of malachite phase with identified disappeared patterns.

$1006.84 \mathrm{~cm}^{-1}$ centered band is attributed to $\mathrm{Si}-\mathrm{O}$ stretching modes [19]. This band shifted to $1060.85 \mathrm{~cm}^{-1}$ for 30 and 45 min activated sample and for $90 \mathrm{~min}$ activated sample this peak positioned at $1064.71 \mathrm{~cm}^{-1}$. Madejova studied FTIR techniques in clay mineral studies for deriving information concerning their structure, composition and structural changes upon chemical modification and stated that $\mathrm{Si}-\mathrm{O}$ stretching modes can be changed upon the structure [20]. At $910 \mathrm{~cm}^{-1}$ centered band belongs to hydroxyl deformation and water bending region and is indicative of the liberation of hydroxyl units from the goethite structure [17]. After $30 \mathrm{~min}$ of mechanical activation this band could not be detected. Prasad et al. stated the mode of $\mathrm{SiO}_{2}$ as a doublet at 779 and $796 \mathrm{~cm}^{-1}$ [21] so that centered at $794.67 \mathrm{~cm}^{-1}$ and $779.24 \mathrm{~cm}^{-1}$ bands for the non-activated malachite coincide with this data. Montmorillonitic clay was treated with $6 \mathrm{M} \mathrm{HCl}$ at $80^{\circ} \mathrm{C}$ by Madejova and $1030 \mathrm{~cm}^{-1}$ band shifted to $1100 \mathrm{~cm}^{-1}$ which was dedicated as $\mathrm{Si}-\mathrm{O}$ stretching vibrations, after $8 \mathrm{~h}$ and band intensity increased with respect to initial stage. Also this band was mentioned as a $\mathrm{Si}-\mathrm{O}$ band for amorphous $\mathrm{SiO}_{2}[20]$. With mechanical activation this band shifted to higher position and increment of the band intensity was detected. As a result it can be said by considering these studies initial crystalline silica phase was turned into amorphous silica by mechanical activation. These results are well matched with X-ray results.

\section{Conclusion}

Mechanical activation by high energy milling caused alteration of the malachite structure. In this study, malachite ore was mechanically activated for 30,45 , and $90 \mathrm{~min}$. Prolonged duration of the process beside the refinement of the particle agglomeration proceeds after 30 min as determined by SEM and particles size analysis. Quartz and malachite phases are present in the ore. With mechanical activation, peak shift, peak broadening and decrement of the intensity were determined for peaks of quartz for all durations and malachite peaks got lost after 30 min mechanical activation. These occurrences are due to the amorphization of the structure by creating disordering via mechanical activation. Disordering in the structure was easily determined by FT-IR method. With mechanical activation, bands of $-\mathrm{OH}, \mathrm{CO}_{3}$ and
$\mathrm{Si}-\mathrm{O}$ changed with respect to band intensity and band center. Weak $-\mathrm{OH}$ bands became linear and one of the $\mathrm{CO}_{3}$ band shifted to higher position that means weaker bonding and another band for $\mathrm{CO}_{3}$ got lost. Intensity of the $\mathrm{Si}-\mathrm{O}$ bands increased with mechanical activation significantly. These bands were attributed to the amorphous silica. As determined from the XRD results, amorphous structure was confirmed with FT-IR by means of missed, broadened shift or difference in intensity bands.

\section{References}

[1] R.L. Frost, Z. Ding, J.T. Kloprogge, W.N. Martens, Thermochim. Acta 390, 133 (2002).

[2] D. Bingöl, M. Canbazoğlu, S. Aydoğan, Hydrometallurgy 76, 55 (2005).

[3] M. Emin Arzutug, M. Muhtar Kocakerim, M. Copur, Ind. Eng. Chem. Res. 43, 4118 (2004).

[4] Z.-X. Liu, Z.-L. Yin, H.-P. Hu, Q.-Y. Chen, Trans. Nonferrous Met. Soc. China 22, 2822 (2012).

[5] M. Samouhos, R. Hutcheon, I. Paspaliaris, Minerals Eng. 24, 903 (2011).

[6] H.R. Watling, Hydrometallurgy 84, 81 (2006).

[7] R.R. Moskalyk, A.M. Alfantazi, Minerals Eng. 16, 893 (2003).

[8] D. Bingöl, M. Canbazoğlu, Hydrometallurgy 72, 159 (2004).

[9] I.A. Kiseleva, L.P. Ogorodova, L.V. Melchakova, M.R. Bisengalieva, N.S. Becturganov, Phys. Chem. Minerals 19, 322 (1992).

[10] K. Wieczorek-Ciurowa, Ju.G. Shirokov, M. Parylo, J. Therm. Anal. Calorim. 60, 59 (2000).

[11] Y. Chen, T. Hwang, M. Marsh, J.S. Williams, Mater. Sci. Eng. A 226-228, 95 (1997).

[12] T. Tunç, F. Apaydın, K. Yıldız, Acta Phys. Pol. A 123, 349 (2013).

[13] P. Pourghahramani, E. Forssberg, Int. J. Miner. Process. 82, 96 (2007).

[14] P. Balaz, Mechanochemistry in Nanoscience and Minerals Engineering, Springer-Verlag, Berlin 2008, p. 123.

[15] R.L. Frost, D.L. Wain, W.N. Martens, B. Jagannadha Reddy, Spectrochim. Acta A 66, 1068 (2007).

[16] I.S. Molchan, G.E. Thompson, P. Skeldon, R. Andriessen, J. Coll. Interf. Sci. 323, 282 (2008).

[17] H.D. Ruan, R.L. Frost, J.T. Kloprogge, L. Duong, Spectrochim. Acta A 58, 479 (2002).

[18] Y.J. Wang, S.L. Pan, X.L. Hou, G. Liu, J. Wang, D.Z. Jia, Solid State Sciences 12, 1726 (2010).

[19] C. Belver, M.A. Banares Munoz, M.A. Vicente, Chem. Mater. 14, 2033 (2002).

[20] J. Madejova, Vibrat. Spectrosc. 31, 1 (2003).

[21] P.S.R. Prasad, K. Shiva Prasad, V. Krishna Chaitanya, E.V.S.S.K. Babu, B. Sreedhar, S. Ramana Murthy, J. Asian Earth Sci. 27, 503 (2006). 